\title{
ECONOMIC GROWTH AND ECONOMIC DEVELOPMENT: CONCEPTS AND MEASURES
}

\author{
Emil E. Malizia*
}

\section{Early Work}

As Amdt $(1981,1987)$ demonstrates, the term economic development, as a subject of scholarly work has rather recent origins. The term is closely affiliated with planned investments and intentional development efforts. Thus the verb, to develop, is used in its transitive sense: people make development happen.

Arndt reviews the diversity of opinion about the process of economic development in relation to desired outcomes. Neoclassical theories and models focused on ways to mobilize resources to achieve economic growth. Most early writers considered increases in gross domestic product (GDP) per capita or in income per capita as adequate measures of good results. On the other hand, theories inspired by Marx or Schumpeter paid greater attention to the underlying structure of the political economy.

As criticisms of intentional development efforts in the Third World grew, scholars began to look more closely at the welfare implications of economic growth. Celso Furtado, while pointing out the accomplishments of the Brasilian economy, noted that the Brasilian people were doing rather badly. Dudley Seers (1969) captured the spirit of this criticism by defining development in human resource terms. Economic development occurs when poverty, unemployment and inequality are reduced while income per capita increases. Jan Drewnowski and others underUNauspices developed direct measures of consumption to substitute for income measures. In a similar vein, some U.S. scholars who were focused on regional development contrasted indicators of social well-being, for example, health and mortality indicators, to average income measures.

Although addressing the normative implications of economic development, the early work failed to resolve the central problem. In the absence of a consensus theory of economic development, consistent measurement was difficult. During the 1970s, in fact, the neoclassical paradigm itself was called into question (Arndt 1987).

Given the inconsistencies among theories used to explain economic development, the recent work by Amos

\footnotetext{
*Professor of Real Estate and Economic Development, Department of City and Regional Planning, University of North Carolina at Chapel Hill.
}

(1990) and Flammang (1990 and 1979) is important. The authors synthesize alternative theories in order topose new meta-theory or conceptual frameworks and, in so doing, advance our understanding of economic development. This author draws on their concepts and frameworks to define economic growth and economic development more clearly and to suggest face-valid measures of these concepts. With better measures of these basic concepts, alternative theories and models of economic development may be tested more rigorously.

\section{The Meanings of Growth and Development}

Amos (1990) combines growth pole, long wave and utility theory to propose a useful and interesting conceptual framework for understanding societal development. He argues for the existence of approximately 100 year development cycles containing two equal long waves. The first is a polarizing cycle focused on a new growth pole producing innovations, and the second is a spreading cycle stimulated by innovation diffusion. As part of these development cycles, Amos considers the role of changing tastes, infrastructure investment and spatial growth and change.

Amos describes innovations in production and transportation that generated growth through concentration from about 1880 to 1930 followed by spread from 1930 to 1980. U.S. corporations were the dominant poles of growth during this long wave. During the long wave that may have begun around 1980, the growth poles may be shifting to Japanese companies, and Pacific Rim countries may become the growth centers over the next 50 years.

Flammang (1979) reviews a considerable amount of development literature. He discusses economic growth and development as related processes based on the structure and functions of the political economy. He summarizes nine different approaches to economic growth and economic development including approaches that define neither term or use the terms interchangably. He offers clarifications by drawing an analogy between biological growth and development. He notes the positive association between growth and development in most instances:

When we refer to economic growth, are not most of us thinking in terms of increase, in terms of the quantity of something measurable? But when we 
use the term "development," are we not trying to imply something in the way of change, something qualitative? These usages seem reasonable, and the quantitative-qualitative distinction is implied, if not stated explicitly, in many of the definitions just surveyed; I suggest that, to most of us, economic growth is a process of simple increase, implying more of the same, while economic development is a process of structural change, implying something different if not something more. (p. 50)

Flammang elaborates a broad, ecological model of development where necessity due to population pressures encourages people to derive more sustenance from the environment. This pressure stimulates human inventiveness and leads to structural change. Flammang argues that this ecological model supports the idea that growth and development may be "alternating processes" (p. 53).

Importantly, Flammang points out that development (structural change) can lead to growth, stagnation or decline. From an ecological perspective, we attempt to adapt to our environment by doing things differently as well as more efficiently. But our environment may or may not adopt the changes we initiate. Moreover, there is considerable variability in the adaption-adoption process which gives rise to winners and losers. The author agrees with Flammang that Neo-Marxists make a contribution by pointing out the two-sidedness of the process: development in one place often leads to underdevelopment in another.

Flammang also suggests "a hierarchy of growth and development" (p. 55) moving from the individual to the firm to the industry and to the economy as a whole. Thus, we can observe and possibly measure growth and development at different levels of aggregation and with different units of analysis. He encourages us to dispel our images of development which almost always reflect our cultural biases and to look at the fundamental and practical problem-solving that leads people to adapt their economy to fit their environment.

Flammang (1990) elaborates his framework by distinguishing niche changing from niche filling activity. The former requires softening of structures and greater internal differences to respond to external changes. The latter requires less differentiation and hardening to accomplish internal adaption. Successful softening leads to dynamic efficiency while successful hardening results in static efficiency. Flammang applies this framework to discuss cyclical development, differences in market and planned systems, and the philosophical roots of his ideas.

Following Flammang, the author (1986) has argued that economic growth and economic development are related but different processes based on the following distinctions:

Growth theories take economic structure as given and focus on short-term changes in the economy. ...The quantity of production, consumption, income, employment or trade is important. Development theories focus on changes in economic structure over the long term. Structural changes may refer to changes in industry mix, product mix, occupation mix, patterns of ownership or control, firm size and age, technologies in use, degree of competitiveness and the like. The quality of production and the distribution of consumption are emphasized. (p. 490)

Many urban economists and regional scientists have drawn similar distinctions. For example, regional scientists often distinguish economic flows from economic structure and tend to focus on structure. Urban geographers and sociologists have long studied spatial structure and structural change over time-morphogenesis. Yet the macroeconomic theories that are applied most frequently in national and regional econometric models focus on flow variables and near-term projections. Such econometric models are far more prominent than models based on theories of economic development.

The measurement of economic development deserves more attention especially as a concept different from economic growth. Although the two are interdependent processes, economic development as described by Amos and Flammang appears to be the more fundamental and basic process. As the level of development increases, welfare indicators such as per capita personal income should improve. Over the long term, growth depends more on development than the reverse; in the near term, development is usually supported by growth. If economic development is the more fundamental, longer-term process, then it should change more slowly than growth and therefore prove more useful for examining change over time. Thus, forecasts based on differences in economic growth and economic development among spatial units in the U.S. should be more accurate than predictions based on growth alone. This conclusion deserves further elaboration.

As the global economy becomes more integrated and the Japanese economy becomes the major growth pole, all areas in the U.S. will be increasingly vulnerable to external political and economic events-events that cannot be easily predicted. Daniel Garnick measures the spatial variation in economic activity over several decades. $\mathrm{He}$ finds that metro area economies have become more volatile in terms of changes in population, income and employment Garnick (1985, 1989). Robert Hopkins and David 
Shulman(1987) study the volatility in metroareaemployment growth from 1976 to 1987 and reach similar conclusions; employment rankings for the 86 largest metro areas are not stable and cannot be used to predict future rankings. Given the conceptual distinctions drawn between economic growth and economic development, the basic assumption here is that the growth performance of local economies in the future will be determined by factors other than previous growth experience. This assumption has particular merit if 1980 marks the beginning of a new polarizing long wave. The key factors should include the fundamental attributes of the area's economy that are related to economic development, which in turn should be useful in forecasting the relative performance of these areas.

Over the long term, economic development and economic growth should be positively associated since both effect the economic prospects and potential of a local area. In most places, greater economic development through successful external adaption will lead to sustained economic growth as internal adaption takes place. Yet at any point in time, softening or the differentiation of economic structure may dominate hardening or the integration of economic structure, hardening may dominate softening, or neither process may be occurring on a noticeable scale. In metro areas becoming more economically viable, adaptive change should lead to growth in certain sectors of the economy and decline in others as internal differences increase. Or at a more disaggregated level, restructuring within local firms may increase dynamic efficiency and growth potential without immediately stimulating the area economy. As a result, the aggregate size of the local economy may not change very much when softening dominates. However, when hardening dominates subsequently, metro growth should accelerate as certain facilities or capabilities become obsolete and more competitive activities achieve success in the market. Thus, a great deal of difference exists between stable metro areas in which flexible restructuring and adaption are taking place and stagnant metro areas experiencing no growth because of weak, rigid economic structures.

Clearly, industrial structure is central to models of economic growth as well as development. Interindustry models, viewed as an elaboration of an export-base growth model, give the fullest articulation of industrial structure and provide estimates of economic growth in terms of output, employment or earnings. Sector theory predicts sectoral shifts to tertiary industries or, more generically, the expansion of income-elastic export industries as productivity improves in established industries.

Interregional trade theory is different in two major respects. It focuses on commodities instead of industries and views substitution effects as comprising its essential dynamic. Although trade theory can be applied empiri- cally at the industry level, it appears more useful to focus on the relationship between comparative costs and income. The assumption is that trade, based both on comparative and absolute advantage, will lead to increased welfare. In empirical terms, regional differences in personal income may be explained by regional differences in productivity and unit costs. Such differences may also reflect differences in level of development as noted above. Measures useful for testing models of economic growth and industrial structure deserve greater attention.

\section{Measures of Growth and Development}

Applying the meanings ascribed to growth and development in the previous section, various measures of the concepts can be proposed. The following discussion emphasizes measures that logically correspond to the underlying concepts, yet recognize data limitations in U.S. regional information. Nodal regions are viewed as the most appropriate units of analysis, either Bureau of Economic Analysis(BEA) areas, labor market areas as defined by the Economic Research Service, Consolidated Metropolitan Statistic Areas, Metropolitan Statistical Areas, Primary Metropolitan Statistical Areas, or New England Combined Metropolitan Areas.

\section{Growth Measures}

Following the practice at the national level, economic growth may be measured by examining various outcomes of the production system. GDP is an appropriate growth measure, and BEA has recently published estimates for all states and D.C. The second best measure currently available for metro areas is employment. BEA, the Bureau of Labor Statistics (BLS) and the Small Business Administration (SBA) maintain and publish employment statistics based on place of work although not with consistent definitions or coverage. Personal income and, in some cases, earnings are performance measures which complement employment change and have significant economic welfare implications. The revised income series recently published by BEA at the county level can be used, for example, as a measure of average material well-being. For most purposes average annual figures adjusted to account for business cycle influences are pertinent for regional growth studies. Growth measures tend to be aggregate measures. Total employment by work-place, for example, is an aggregate measure summed over all reporting establishments in the constituent metro counties. Personal income is an aggregate measure of flows to households residing in the area.

Another concept related to economic growth may be introduced at this juncture-economic stability. Since the 
work of Conroy (1975), regional scientists have examined growth and stability in a portfolio context (e.g. Brewer 1984) or with other measures of diversification (e.g. Kort 1981, Keinath 1985 and Attaran 1986). It appears useful to consider growth as the return to the region and stability as the risk related to that reward. With time series data on employment, income and earnings available for appropriate units of analysis, the analyst may construct several stability measures. Kort, for example, used smoothed quarterly employment data to measure relative fluctuations from the trend line for his sample of metro areas.

\section{Development Measures}

Unlike economic growth which may be measured as economic outcomes occurring over time and resulting from production and consumption activities in metroareas, economic development is more complicated. It must be measured more broadly to account for the relevant qualitative and structural features of the local economy. Absent a consensus theory of economic development, the analyst cannot propose a definitive set of measures. Yet Amos' framework and Flammang's ecological approach as elaborated previously are suggestive.

Although the metro area or nodal region remains the appropriate unit of analysis, few measures are actually attributes of metro units. Most measures of economic development discussed below focus on establishments and firms and, to a lesser extent, on the metro labor market. The measures address the structure of industries, products, companies and occupations in the metro area.

Clearly, shift-share analysis is a useful way to examine the influence of industrial structure on economic growth and to measure the growth potential of industry mix. The industry mix term is clearer than the residual effect which is often used as an indicator of competitive advantage. Productivity measures are more difficult to create. GDP per employee would be interesting if state estimates could be "stepped down" to the metro level. Value-added in manufacturing per production hour or wage dollar has reasonable face validity although differences in capital intensity introduce confounding effects. Regional scientists should collaborate and propose best available measures of industrial structure and productivity at the metro level as indicators of static efficiency.

Product cycle theory is widely used to explain regional growth from a structural perspective but poses difficult measurement problems due to ambiguities about the proper level of disaggregation. The simplest approach is to focus on manufacturing, where the hypotheses most easily apply, and examine the structure of establishments. With County Business Patterns (CBP) data, the analyst can develop overall and industry-specific employment size distributions for establishments by metro area. The U.S. Establishment and Enterprise Microdata (USEEM) file available from SBA can be used to generate complementary establishment measures. With special tabulations of these data, one can identify single establishment firms, headquarters, branches, or subsidiaries among manufactures and other sectors across metro areas. The dominance of branches and, to a lesser extent, subsidiaries are evidence of standardized products and routine production. The preponderance of headquarters implies the presence of products in earlier stages of development. These CBP-and USEEM-based measures should be considered reasonable expressions of the product cycle hypothesis if they turn out to be correlated significantly with metro area income and significant wage levels. However, in an era of corporate restructuring, headquarters may be less significant than $R$ \& D facilities and expenditures as an indicator of new product development.

Recent work by Wilbur and Philip Thompson (1985) may shed additional light on the measurement of economic development. They pose five functional types of metro areas largely related to occupational structure. Cities are centers of entrepreneurship, central administration, $R \& D$, precision production, or routine production. They point out that industry mix may change considerably without altering fundamentally the functional-occupational orientation of the area. (The same point may be made with respect to product cycle theory.) Using census information on occupational structure, the Thompson approach suggests several useful occupational measures that may be related to productivity and growth due to differences in comparative costs. Metro areas dominated by either routine or precision occupations which include laborers, operatives and technicians, may have lower relative costs and higher efficiency. The percentage of adults with high school education or less should be correlated with these occupational measures. Technical and professional occupations associated with $R$ \& $D$ centers should indicate places generating newer products as suggested by product cycle theory. However, the author has tested the relationship between occupational mix in 1970 and 1980 and subsequent employment change without getting encouraging results.

Neo-Marxist theories offer interesting insights about the economic development process but few good measures given available data. For example, the concentration of power as reflected in the distribution of wealth among metro area residents may deserve attention, but these data are not available subnationally.

Entrepreneurship theories, including Schumpeter, are more promising. The qualitative structural change associated with economic development may be related to resilience and innovation potential in the metro area which 
in turn may be associated with creativity and initiativetaking at the individual level (Shapero 1981). In the temporal process of creative destruction innovative areas should predominate among the winners. Jacobs (1969), with her concept of developmental work, contrasts Birmingham and Manchester in the 19th century - the innovative city versus the efficient city - and argues for the long-term viability of the former. Clearly, the concept of resilience is quite consistent with the ecological model and the contrast between dynamic and static efficiency put forward by Flammang. The author sees resilience depending on the differential abilities of individuals and firms to respond to threats or seize opportunities, abilities which vary from area to area.

Unfortunately, resilience is difficult to measure. The author has tested the rate of reduction in absolute unemployment across larger metro areas after the recessions of 1974-75 and 1981-82. In both instances, the measure appears more related to industry mix than to long term innovation potential (Victor and Vemez 1981). A more promising approach may be to use the USEEM database to add job gains to job losses across all establishments in each metro area. Higher rates or absolute values would indicate greater turbulence which may be an important aspect of resilience. Clearly, a face valid measure reflecting an area's capacity to bounce back from economic adversity would be quite useful.

On the opportunity side, the author considers a measure developed by David Birch reasonably good. Using the Dun \& Bradstreet data comparable to the USEEM database, he calculates the percentage of relatively new firms that are rapidly growing by metro area (Inc. 1988). High survival and expansion rates are evidence of support for initiative taking. Establishment birth rates or incorporation rates may also be used but are inferior in this regard because amount of start up activity is less important than the success of new companies. As an alternative, $\mathrm{CBP}$ data may be used to analyze employment change by establishment size controlling for industry mix in each metro area. One approach would be to compare metro employment change over time for a smaller establishment size range to U.S. change among the same cohort of establishments using shift-share analysis. After accounting for industry mix effects, the remaining local effect term would be used as an indicator of entrepreneurial vitality.

As for innovation potential, the author would nominate the percentage of adults with at least college education and percentage of management, professional and research occupations to support innovation, following Thompson's work and others. Drawing from a dissertation which tabulated employment in technology-based firms from Duns data by metro area in the mid 1970s (Graham 1981), the author calculated the per capita measure to reflect the $R$ \& $D$ orientation of the area. It is also possible to track federal $R$ \& $D$ expenditures by metro area. Finally, the percentage of single establishment firms may be measured from the USEEM data. Some argue that this measure is associated with degree of local innovativeness.

From an ecological perspective, the supportiveness of the metro area environment to both dynamic and static efficiency should be measured directly. For this purpose, the literature on human ecology has more to offer than the concepts of agglomeration economies and the urban incubator hypothesis because measures presented in the literature for the latter concepts are minimal and weak. Regional scientists should give the measurement of these concepts more serious attention.

From the classical ecology concern with functional specialization comes the concepts of industrial mix, which was dealt with above, and diversity. This literature also presents the related concepts of dominance and centrality. Finally, another literature discusses the issue of quality of life at the metro level. (See Myers (1988) for an overview).

Taking each concept in turn, diversity which is an attribute of a metro economy (not diversification which should be considered the process that changes the level of diversity) has been measured in several ways. The portfolio approach (Conroy 1975) is suggestive but quite data intensive. The entropy measure is consistent with the ecological work and easier to formulate (Kort 1981). The author has experimented with the coefficient of specialization, ogive and other measures without achieving encouraging empirical results.

The author argues that these measures, while very useful, are much too narrow because they only deal with industries. Diversity, considered generically as the degree of variety or internal differences in the local economy, can be measured for occupations, products and companies as well as for process technologies or forms of production. One can apply the entropy measure, for example, to indicate the diversity of occupational mix. The percentage of single establishment firms and the establishment size distribution noted above may reflect diversity in business ownership and control. It is also possible to use Duns Market Identifiers data to determine the concentration of employment controlled by major employers (say companies with at least $2 \%$ of total labor force), but the data are very expensive. More work is needed to identify broader measures of economic diversity conceived as indicators of variety and internal differences. As such, more diverse areas should support adaptive innovation while less diverse places may be compatible with efficient production.

Dominance is supposed to reflect the economic importance of a place. In a world consistent with central place 
theory, the highest order center is most dominant. In growth pole theory, it is the growth center. In the real world, headquarter centers and other centers of central administration play this role. Following Noyelle (1983) the author finds that the number of accountants, directors and principals associated with the "Big Six" accounting firms is an excellent measure of dominance. This measure is highly correlated with headquarters employment, percent managers, and more importantly, the various producer services thought to be essential for innovation. Thompson and Thompson (1985) calls these developmental services.

Physical linkages support these economic linkages as discussed by Amos (1990). In the global economy of the 1980 s and 1990 s, air transportation and telecommunications reflect the centrality of a metro area. Moss (1986) has shown that the latter are primarily centralizing and reinforcing the importance of the largest cities. Air transportation is the key mode in the global economy, and major hub areas are the more central, especially in the wake of airline deregulation in the U.S. Hubs with non-stop access to the Pacific Rim may be the most important. Air transportation and telecommunications appear more critical for adaptive innovation. Efficient highway, rail and water transport plus good telephone service should support efficient production.

Finally, quality of life is viewed as an important related aspect of economic development. However, the author suggests attending to other concepts first, having devoted considerable time to quality of life measurement without arriving at particularly good indicators. One measure worth examining may be the median cost of housing in relation to income by metro area. Another is cost of living as measured for reporting areas by the American Chamber of Commerce Researchers Association (ACCRA). The former measure correlates with other amenity/disamenity factors across metro areas. The latter reflects comparative costs.

Considerable interaction no doubt exists among the ecological and structural measures which must be sorted out for proper model specification. Yet at the conceptual level, one should picture metro area development as standing on two legs-efficient production (static efficiency) and adaptive innovation (dynamic efficiency) —and resting upon a foundation of structural and ecological factors which together determine the flexibility and creativity or the firmness and productivity of the metro economy.

\section{Conclusions}

In summary, the qualitative and structural measures of economic development proposed here represent the author's attempt to arrive at face valid development indi- cators which may be generally useful in empirical and policy analysis and particularly helpful to understand longterm metro area growth and welfare performance. Measures related to productivity and industrial composition should be useful in testing hypotheses about economic growth outcomes. Measures of resilience and innovation potential are indicators of adaptive innovation that should be related to economic welfare and sustained growth. Measures of the local environment such as diversity, dominance and centrality are important for understanding a metro economy's long-term viability and fundamental strength.

This paper does not contain a new theory of economic development. But drawing on the ecologicalstructural approach, it offers numerous measures of economic development which can be distinguished from measures of economic growth. With these measures, regional scientists may be better able to examine secular change in metro economies with hypotheses drawn from structural theories of economic development. For short-run analysis and near-term forecasting, economic growth measures may well suffice. But for understanding the economic fundamentals of metro economies and forecasting longterm performance, hypotheses fleshing out aspects of economic development are essential.

\section{References}

Amos, Orley M., Jr. "Regional Cycles and Unbalanced Regional Growth: A Synthesis of Growth Pole and Long Wave Theories." Review of Regional Studies, 20 (1990).

Amdt, H. W. "Economic Development: A Semantic History," EDCC, 29:(1981) 457-466.

- Economic Development: The History of an Idea. Chicago: University Press, 1987.

Attaran, Mohsen. "Industrial Diversity and Economic Performance in U.S. Areas." The Annals of Regional Science, 20 (1986) 44-54.

Brewer, H. L. "Regional Economic Stabilization: An Efficient Diversification Approach." Review of Regional Studies, 14 (1984) 8-21.

Conroy, MichaelE. "The Concept and Measurement of Regional Industrial Diversification." Southern Economic Journal, 41 (1975) 492-505.

Flammang, Robert A. "Economic Growth and Economic Development: Counterparts or Competitors?" EDCC, 28 (1979) 47-61.

- "Development and Growth Revisited." Review of Regional Studies, 20 (1990).

Garnick, D. H. "Patterns of Growth in Metropolitan and NonMetropolitan Areas: An Update." Survey of Current Business, 65 (1985) 33-38. 
- "Growth in Metropolitan and Nonmetropolitan Areas:

An Update." Survey of Current Business, 69 (1989) 37-38.

Graham, Stephen G. "The Determinants of the Geographical Distribution of the Formation of New and Small Technology-Based Firms." Unpublished Dissertation, Michigan State University, 1981.

Hopkins, R. and Shulman, D. "Ranking Metropolitan Growth." Salomon Brothers Inc. June 1987.

Inc. "Metro Report: Hot Spots." March 1988. 6 pages.

Jacobs, Jane The Economy of Cities. New York: Random House, 1969 especially 86-97.

Keinath, William E. "The Spatial Component of the PostIndustrial Society." Economic Geography, 61 (1985) 223240.

Kort, John R. "Regional Economic Instability and Industrial Diversification in the U.S." Land Economics, 57 (1981) 596-608.
Malizia, Emil E. "Economic Development in Smaller Cities and Rural Areas." JAPA 52 (1986) 489-499.

Moss, M.L. "Telecommunications and the Future of Cities." Land Development Studies, 3 (1986) 33-44.

Myers, Dowell "Building Knowledge About Quality of Life for Urban Planning." JAPA, 54 (1988) 347-358.

Noyelle, Thierry J. "The Rise of Advanced Services." JAPA, 49 (1983) 280-290.

Seers, D. "The Meaning of Development," International Development Review, 11 (1969) 2-6.

Shapero, Albert "Entrepreneurship: Key to Self-Renewing Economies." ED Commentary, 5 (1981) 19-23.

Thompson, Wilbur R. and Thompson, PhilipK. "From Industries to Occupations: Rethinking Local Economic Development." ED Commentary, 9 (1985) 12-18.

Victor, RichardB. and Vemez, Georges. "Employment Cycles in Local Labor Markets.” Unpublished paper, Rand Corporation, March 1981. 